\title{
Análise da estrutura e distribuição da cobertura vegetal das caatingas em diferentes áreas de sequeiro no Vale do São Francisco (Bahia e Pernambuco) nas últimas três décadas
}

\author{
Analysis of the structure and distribution of caatingas vegetable coverage in \\ different areas of drought in the São Francisco Valley (Bahia and \\ Pernambuco) in the last three decades
}

\author{
José Welton Coelho de Aquino ', Antônio Marcos dos Santos "
}

\section{RESUMO}

Nos últimos anos a redução da cobertura vegetal das caatingas vem chamando atenção e incentivando estudos que buscam entender a dinâmica de retração de suas coberturas vegetais. Nesse sentido, o objetivo desse estudo é analisar a estrutura da cobertura vegetal em diferentes áreas das caatingas nas últimas três décadas, e investigar os fatores que possam influenciar o comportamento da distribuição da cobertura vegetal em duas áreas de monitoramento nos estados de Pernambuco e Bahia. Para isso, foram utilizadas imagens de satélite obtidas a partir dos sensores TM e OLI, acoplados ao satélite Landsat 5 e 8, respectivamente, as quais foram submetidas a calibração radiométrica, extração do Índice de Vegetação Ajustada ao Solo (IVAS) e a classificação supervisionada. O estudo mostrou que ao longo dos aproximados 30 anos de estudo, houve grande variabilidade da dinâmica de mudanças nas áreas de caatingas, porém prevalecendo uma tendência de diminuição da Caatinga Fechada sendo substituída pelas caatingas Semiaberta e Caatinga Aberta. Verificou-se, também, que principalmente nos últimos 11 anos ocorreu aumento das áreas de agricultura / pastagem / caatinga Gramíneo Lenhosa. Essas mudanças são impulsionadas por alterações antrópicas, principalmente pelo crescimento de áreas de pastagens e pela diminuição dos totais pluviométricos nos últimos anos.

Palavras-chave: Vegetação das terras secas; Desertificação; Degradação da cobertura vegetal; Sensoriamento Remoto

\section{ABSTRACT}

In recent years, the reduction of the vegetation cover of the caatingas has been attracting attention and encouraging studies that seek to understand the retraction dynamics of its plant covers. In this sense, the objective of this study is to analyze the structure of the vegetation cover in different areas of the caatingas in the last three decades, and investigate factors that may influence the behavior of plant cover distribution in two monitoring areas in the states of Pernambuco and Bahia (Brazil). For this, satellite images obtained from the TM and OLI sensors, coupled to the Landsat 5 and 8 satellite, were submitted to radiometric calibration, extraction of the Soil Adjusted Vegetation Index (IVAS) and supervised classification. The study showed that

Mestrado pela Universidade de Pernambuco em Ciência e Tecnologia Ambiental para o Semiárido. Tem experiência na área de Geografia, com ênfase em Ciências Ambientais e Sensoriamento Remoto.. E-mail. welton.aquino@hotmail.com ORCID: https://orcid.org/0000-0001-8718-0654

" Doutor em Geografia pela Universidade Federal de Pernambuco.Professor Adjunto do curso de Geografia e do Programa de PósGraduação em Ciência e Tecnologia Ambiental para o Semiárido da Universidade de Pernambuco, campus Petrolina. E-mail. ntonio.santos@upe.br ORCID https://orcid.org/0000-0002-5968-9880 
over the approximately 30 years of study, there was great variability in the dynamics of changes in the caatinga areas, but prevailing a trend of decrease in the Closed Caatinga being replaced by the Semi-open Caatinga and Open Caatinga. It was also found that mainly in the last 11 years there has been an increase in the areas of agriculture / pasture / gramíneo-woody caatinga. These changes are driven by anthropic changes, mainly for the growth of pasture areas and the decrease of total rainfall in recent years.

Keywords: Dryland vegetation; Desertification; Degradation of plant cover; Remote Sensing

\section{INTRODUÇÃO}

As Florestas Tropicais Sazonalmente Secas (FTSS) compreendem a $42 \%$ de todas os tipos de florestas tropicais no mundo e sofrem severamente com o desmatamento (VALDEZ-HERNÁNDEZ et al., 2014). As altas densidades populacionais humanas, que dependem da terra e recursos florestais para sua subsistência influenciaram, em parte, para que as florestas secas fossem submetidas a degradação e fragmentação (MORALESBARQUERO et al., 2015). Aproximadamente, 50\% das FTSSs foram convertidas em outros usos, o que torna esse ambiente um dos mais ameaçados em todo o mundo (LÓPEZBARRERA, et al., 2014).

Estudos verificaram a diminuição da cobertura vegetal das FTSSs na África, na América Central e no México (MAYES et al. 2015; PORTILLO-QUINTERO; SMITH, 2018). Por outro lado, mudanças nas políticas públicas e tendências na migração populacional permitiram um ganho florestal de 4,9\% entre 2000 a 2007 em uma área do México (LÓPEZ-BARRERA, et al., 2014), e a diminuição da perda florestal após a implantação de uma área de proteção ambiental em Gana, África Ocidental (JANSSEN et al., 2018).

Não diferente, de outros ambientes florestais secos, o Domínio da Caatinga vem sendo reduzido nos últimos anos (COELHO et al., 2014; FERNANDES et al., 2015). Diversas estimativas apontam que entre $30,4 \%$ a $51,7 \%$ da sua cobertura vegetal foram desmatadas e as restantes estão sob intenso processo de degradação (CASTELLETTI et al., 2003; MMA, 2011; BEUCHLE, 2015).

A degradação da vegetação das caatingas contribui no processo de desertificação (SOUZA, 2019). A desertificação pode ser definida como a degradação das terras secas promovidas pelas ações humanas e/ou pelas intempéries ligadas as variabilidades ou mudanças climáticas (UNCCD, 1994). 
Fatores antrópicos como a pecuária, a extração da madeira para produção de carvão e lenha e práticas agrícolas inadequadas vem sendo apontados como ameaças a conservação do Domínio da Caatinga, ou seja, alguns dos responsáveis por sua degradação (COUTINHO, 2006; SILVA; MENDONÇA, 2014; RITO et al., 2017; ANTONGIOVANNI et. al., 2018; VENTICINQUE; FONSECA, 2018).

O que foi relatado no parágrafo anterior contribui com a degradação das áreas de Caatinga e consequentemente, vem contribuindo com o processo e/ou ampliando os riscos de desertificação no semiárido brasileiro.

Apesar de alguns estudos sobre as Caatingas apontarem ganho da cobertura vegetal nos últimos anos, esse aumento refere-se ao crescimento das espécies vegetais de características arbustivas incluindo espécies pioneiras sobre áreas que anteriormente, apontavam para solos exposto (AIDE; CLARK, 2013; AIDE et. al., 2013; REDO, et. al., 2013; MARINHO et. al. 2016; SCHULZ et. al., 2017). Outra justificativa para aumento da cobertura vegetal em algumas áreas anteriormente desmatadas são as variações das precipitações pluviométricas (SCHULZ et. al., 2017).

Diante da importância do Domínio da Caatinga para a estabilidade ambiental, além de ser fonte de recursos sustentáveis para comunidades humanas ali inseridas e sua importância cultural, torna-se relevante a necessidade de compreensão da dinâmica de uso e cobertura das terras desse ambiente, verificando não somente as taxas de desmatamento como também, mudanças na estrutura da vegetação e, entender sua relação com o processo de desertificação.

Nesse sentido, o objetivo desse estudo é analisar a estrutura da cobertura vegetal em diferentes áreas de caatingas nas últimas três décadas, e investigar os fatores que possam influenciar o comportamento da distribuição da cobertura vegetal em duas áreas de monitoramento nos estados de Pernambuco e Bahia. 


\section{MATERIAIS E MÉTODOS}

\section{1 Área de estudo}

O estudo foi desenvolvido em duas áreas de monitoramento, uma no Povoado de Simpatia, município de Petrolina - Pernambuco, abrangendo 10.000,26 (ha), e outra na Estação de Monitoramento da Microbacia do Sítio Romão, abrangendo uma área de 403,02 (ha), localizada entre os municípios de Casa Nova - Bahia e Afrânio estado de Pernambuco (Figura 1). As áreas de estudos foram selecionadas por serem monitoradas pelo Grupo de Trabalho em Geotecnologias, Monitoramento Ambiental e Ensino da Universidade de Pernambuco campus Petrolina.

Figura 1 - Mapa de Localização da área de estudo
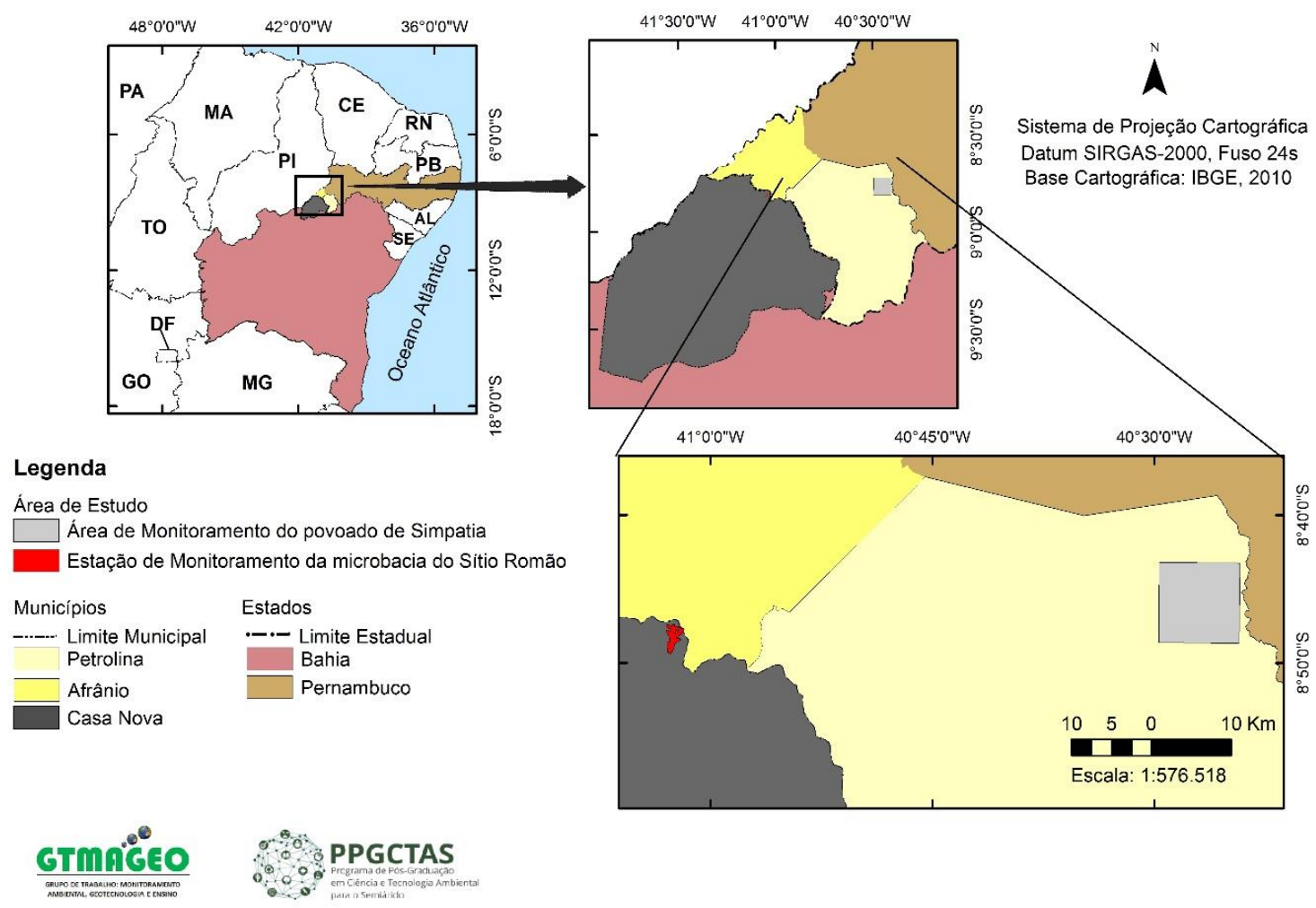

Fonte: Organização dos autores (2019).

O município de Petrolina ocupa uma área de $4.561,874 \mathrm{~km}^{2}$ e possui uma população estimada de 343.865 habitantes de acordo com o Instituto Brasileiro de Geografia e 
Estatística (IBGE, 2018). A sede do município está localizada entre as coordenadas geográficas de $09^{\circ} 23^{\prime} 35^{\prime \prime} \mathrm{S}$ e $40^{\circ} 30^{\prime} 27^{\prime \prime} \mathrm{W}$ (BELTRÃO et. al., 2005b).

O município de Afrânio ocupa uma área de 1.490,594 km² e possui uma população estimada de 19.456 habitantes de acordo com o IBGE (2018). A sede do município entre as coordenadas geográficas de $08^{\circ} 30^{\prime} 54^{\prime \prime} \mathrm{S}$ e $41^{\circ} 00^{\prime} 18^{\prime \prime} \mathrm{W}$ (BELTRÃO et. al., 2005a).

Já o município de Casa Nova - Bahia ocupa uma área de 9.647,072 km², possui uma população estimada de 71.366 habitantes, segundo o IBGE (2018). A sede do município

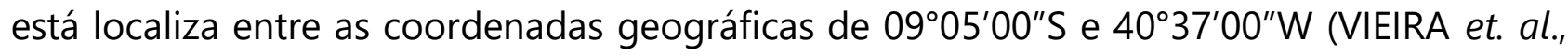
2005).

O clima predominante nos três municípios é o tropical semiárido com média pluviométrica anual em torno de 431,8 mm em Petrolina-PE e Afrânio-PE, e em torno de 490 mm em Casa Nova-BA. As chuvas são concentradas no verão, e a temperatura média anual de $26,2^{\circ} \mathrm{C}$. Ambos estão inseridos na unidade geoambiental da Depressão Sertaneja com vegetação predominante do tipo arbórea caracterizada pelas Caatingas Hiperxerófilas com trechos de Florestas Caducifólias (BELTRÃO et. al., 2005a; BELTRÃO et. al., 2005b; VIEIRA et. al., 2005).

\subsection{Procedimentos metodológicos}

Para o mapeamento da cobertura vegetal e uso das terras na área de estudo, foram utilizadas imagens orbitais geradas pelos sensores TM (Thematic Mapper) e OLI (Operational Land Imager), acoplados no satélite Landsat 5 e Landsat 8, respectivamente. As imagens foram adquiridas a partir da plataforma do Serviço Geológico dos Estados Unidos (USGS). Para cada área de estudo foram selecionadas imagens com intervalos aproximados de dez anos, entre elas, levando em consideração, principalmente, o período chuvoso, quando a vegetação se encontra com o maior quantitativo de folhas. Além desse fator, foram selecionadas imagens com o mínimo de interferência de nuvens. O Quadro 1 apresenta a descrição e caracterização dos produtos orbitais empregado no estudo. 


\section{Quadro 1 - Descrição e caracterização dos produtos orbitais empregado no estudo}

\begin{tabular}{|cccc|}
\hline Área & Sensor & Ponto & Período \\
\hline Área de & TM & $217 / 66$ & $23 / 05 / 1987$ \\
Monitoramento do & TM & $217 / 66$ & $09 / 12 / 1996$ \\
Povoado de Simpatia & TM & $217 / 66$ & $02 / 02 / 2005$ \\
& OLI & $217 / 66$ & $22 / 05 / 2016$ \\
Estação de & TM & $217 / 66$ & $23 / 05 / 1987$ \\
Monitoramento da & TM & $218 / 66$ & $17 / 11 / 1997$ \\
Microbacia do Sítio & TM & $217 / 66$ & $22 / 01 / 2007$ \\
Romão & OLI & $218 / 66$ & $16 / 03 / 2018$ \\
\hline
\end{tabular}

Fonte: INPE (2018).

Após a obtenção das imagens, as mesmas foram submetidas ao processo de empilhamento das bandas espectrais, correção georreferencial (registro) e recorte das áreas de estudo, processo realizado através do software ARCGIS 10.6 (versão demonstrativa).

Em seguida as imagens foram submetidas à calibração radiométrica, realizando-se o processo de conversão do número digital em radiância espectral monocromática Li para as bandas reflectivas do TM Landsat 5, através da equação proposta por Allen et al. (2002) e Chander e Markham (2003) (equação 1) e, posteriormente, foi obtida a reflectância planetária conforme Chander e Markham (2003) (equação 2). As imagens oriundas do satélite Landsat 8 não precisaram passar pelo cálculo da radiância (equação 1).

$$
L_{\lambda i}=a_{i}+\frac{b_{i}-a_{i}}{255} N D
$$

\section{Equação 1}

Em que: $a$ e $b$ são as radiâncias espectrais mínima e máxima $\left(\mathrm{W} / \mathrm{m}^{2} / \mathrm{sr} / \mu \mathrm{m}\right)$, respectivamente, $N D$ é a intensidade do pixel (0 a 255) e $i$ corresponde as bandas do sensor TM Landsat.

$$
P_{\lambda i}=\frac{\pi \cdot L_{\lambda i}}{K_{\lambda i} \cdot \cos Z \cdot d_{r}}
$$

Equação 2

Em que: $L_{\lambda i}$ é a radiância espectral de cada banda, $K_{\lambda i}$ é a irradiância solar espectral de cada banda no topo da atmosfera $\left(\mathrm{W} / \mathrm{m}^{2} / \mathrm{mm}\right), Z$ é o ângulo zenital solar e $d_{r}$ é o quadrado da razão entre a distância média Terra-Sol (ro) e a distância Terra-Sol (r) na data de aquisição da imagem (DSA), que segundo lqbal (1983), é obtida através equação 3. 


$$
d_{r}=1+0.033 \cos (D S A \cdot 2 \pi / 365) \quad \text { Equação } 3
$$

Em seguida, para cada imagem, foi aplicado o Índice de Vegetação Ajustado ao Solo (IVAS) desenvolvido por Huete (1988) (equação 4). Apesar do IVDN (Índice de Vegetação por Diferença Normalizada) ser o índice mais utilizado para estudos sobre a cobertura vegetal (RÊGO et. al., 2012; LOPES, et al., 2020), o IVAS é considerado o mais apropriado para os estudos das vegetações das terras secas, pois minimiza os efeitos espectrais do solo no sinal da vegetação (FATIHA et. al., 2013; RIBEIRO et. al., 2016; LOPES, et al., 2020).

$$
I V A S=\frac{(1+L)\left(P_{i v}-P_{v}\right)}{\left(L+P_{i v}+P_{v}\right)} \quad \text { Equação } 4
$$

Em que: $P_{i v}$ e $P_{v}$, correspondem as faixas espectrais do infravermelho próximo e do visível (vermelha), e o $L$ representa o valor utilizado para ajuste da interferência do solo sobre a reflectância da vegetação. O citado fator de ajuste, segundo Huete (1988), varia entre 0,25 a 1,0, sendo que quanto maior o valor menor deverá ser a densidade da cobertura vegetal. Para esse estudo foi utilizado o fator de ajuste $L=0,5$ valor que representa uma vegetação com densidade intermediária sendo o mais frequentemente utilizado (ALI et. al., 2018).

Com os resultados obtidos, foi realizada a associação dos intervalos de classes do IVAS com os tipos de uso e ocupação das terras observados em campo. Em relação a nomenclatura utilizada para classificar as estruturas de uso e cobertura das terras da área de estudo, a mesma foi adaptada da metodologia de Cavalcanti (2014) e do estudo de Santos e Santos (2019) e estão descritas no Quadro 2.

\section{Quadro 2 - Descrição das classes de uso e ocupação das terras empregadas nesse estudo}




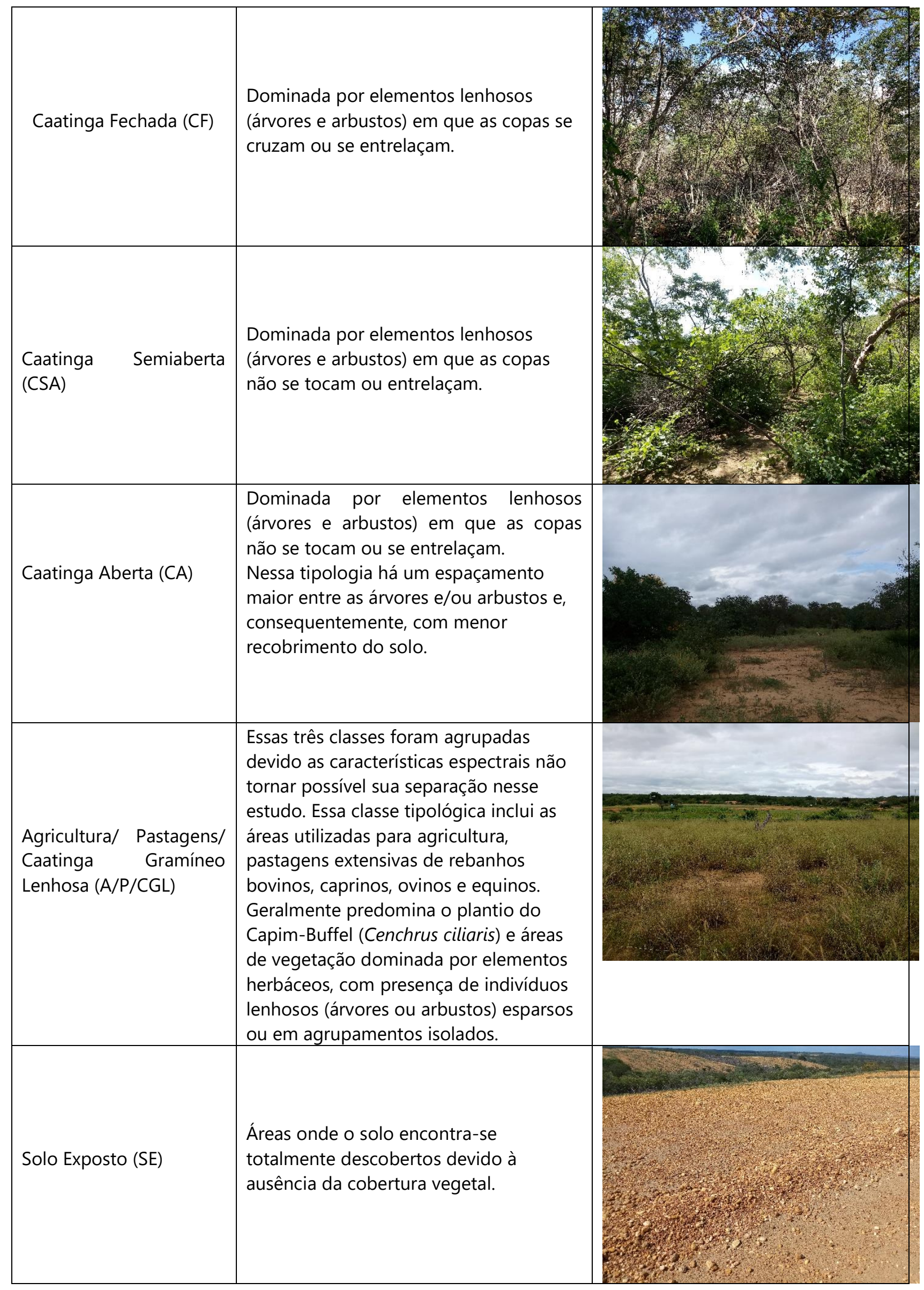


Fonte: Calvacanti (2014) e Santos e Santos (2019). Adaptado para realidade de estudo pelos autores (2019).

Para validação do mapeamento e ajustes dos intervalos das classes do IVAS foi aplicado o Índice Kappa nas imagens mais recentes. O Índice Kappa é calculado a partir do uso de uma matriz de confusão (COHEN, 1960). Esta, por sua vez, é gerada após a medição da acurácia dos resultados do mapeamento com os dados obtidos em campo. Os dados de campo foram coletados através do registro de pontos no aparelho receptor de GPS e, cada ponto, foi classificado de acordo com as classes de usos utilizadas nesse estudo (Quadro 2). Para esse estudo foram coletados 100 pontos para área de monitoramento do povoado de Simpatia e 50 pontos na Estação de Monitoramento da Microbacia do Sítio Romão.

Em posse dos pontos de localização com suas devidas coordenadas, preencheu-se a matriz de confusão, onde foram associadas às ocorrências de acertos e erros da imagem classificadas com o IVAS no mapeamento em relação à referência terrestre. O Coeficiente de Kappa pode ser obtido através da equação 5.

$$
K=\frac{N \sum_{i=1}^{r} X_{i i}-\sum_{i=1}^{r}\left(X_{i+} * X+i\right)}{N^{2}-\sum_{i=1}^{r}\left(X_{i+} * X_{+i}\right)} \quad \text { Equação } 5
$$

Em que: $K$ corresponde ao Coeficiente Kappa de concordância; $N$ refere-se ao número de observações (pontos amostrais); $r$ é o número de linhas da matriz de erros; xii são as observações na linha $i$ e coluna $i ; x i+$ corresponde ao total marginal da linha $i ; x+i$ é o total marginal da coluna i.

A concordância do coeficiente Kappa foi realizado de acordo com a escala proposta por Landis e Koch (1977) (Quadro 3). Destaca-se que a validação das imagens mais recentes serviu de referência para a classificação das imagens antigas.

\section{Quadro 3 - Nível de Concordância do índice Kappa}

\begin{tabular}{|cc|}
\hline Índice Kappa (IK) & Nível de concordância \\
\hline$<0,0$ & Ruim \\
$0,0-0,02$ & Leve \\
$0,21-0,4$ & Razoável \\
$0,41-0,6$ & Moderado \\
$0,61-0,8$ & Substancial \\
\hline
\end{tabular}


$0.81-1$

Quase perfeito

Fonte: Landis e Koch (1977).

Destaca-se que o IVAS é sensível a quantidade de água disponível nas folhas da vegetação. Esse índice sofre variações de acordo com as precipitações pluviométricas (SANTOS, 2018). Essa variação pode ocorrer em um curto período de tempo, como identificado no estudo de Gameiro et. al., (2016), o qual verificou reduções nos valores do IVAS em período seco em relação ao período chuvoso nas imagens do mesmo ano. Essa redução também foi observada em algumas imagens desse estudo.

Para confirmar que essa redução é devido aos baixos índices pluviométricos foram coletadas precipitações pluviométricas a partir dos dados da APAC-PE (Agência Pernambucana de Águas e Clima do estado de Pernambuco), dos 90 dias antecedentes as imagens e divididas a cada 30 dias. Para as imagens com baixos valores de IVAS devido à baixa precipitação antecedente foi desenvolvido intervalos de classes diferentes para elas.

Quando essa redução foi em imagens recentes aplicou-se a validação através do índice Kappa conforme mencionado anteriormente, no entanto em imagens antigas foi utilizada uma imagem correspondente a um período com alta precipitação antecedente com diferença máxima de três meses com a imagem utilizada nas áreas de estudo, porém não usada para a análise devido à grande interferência de nuvens. Ao obter essa imagem foi realizado um recorte nas áreas de estudo ou próximo a elas que não foi influenciada pelas nuvens e realizou-se o processamento da imagem através da calibração radiométrica (equação 1 e 2) e, consequentemente a aplicação do IVAS (equação 4).

A partir de então, a área recortada foi comparada com a imagem que utilizada para o mapeamento de uso e ocupação das terras, processada no mesmo método da imagem do período chuvoso e na mesma área de recorte, e posteriormente, os intervalos foram ajustados de acordo com a mesma extensão encontrada na imagem de período de alta precipitação pluviométrica. Por fim, para a validação do ajuste de intervalos, foi aplicado o índice Kappa entre as imagens.

Para verificar a influência das ações antrópicas foram coletados dados do IBGE sobre agropecuária na área de estudo. Para isso, levantou-se o histórico da quantidade de 
rebanho de caprinos, ovinos e bovinos e a área de lavoura temporária e pastagens nos municípios de Petrolina - PE e Casa Nova - BA. Foram utilizadas, também, observações em campo para verificar possíveis fatores que determinam mudanças no uso e ocupação das terras.

Outro dado que serviu de base para avaliar os padrões das classes de usos e cobertura das terras foram as precipitações pluviométricas. Para isso, foram coletadas informações da PCD (Plataforma de Coleta de Dados) de Petrolina mantida pela APAC (Agência Pernambucana de Águas e Clima do Estado de Pernambuco). Os dados coletados correspondem ao recorte histórico entre os anos de 1987 a 2016, sendo que foram aproveitados os valores apenas dos meses chuvosos anuais (janeiro, fevereiro, março, abril e dezembro do ano anterior).

\section{RESULTADOS E DISCUSSÃO}

\subsection{Mudanças de uso das terras na área de monitoramento do povoado de Simpatia}

Ao analisar os índices pluviométricos (Figura 2) para a área de monitoramento do povoado de Simpatia verificou-se que as imagens dos anos de 1987 a 2005 foram coletadas em período com alta precipitação pluviométrica antecedente e, no ano de 2016, com baixa precipitação antecedente.

Figura 2 - Quantificação da precipitação pluviométrica no município de Petrolina nos dias antecedentes à imagem de acordo com dados da APAC-PE.

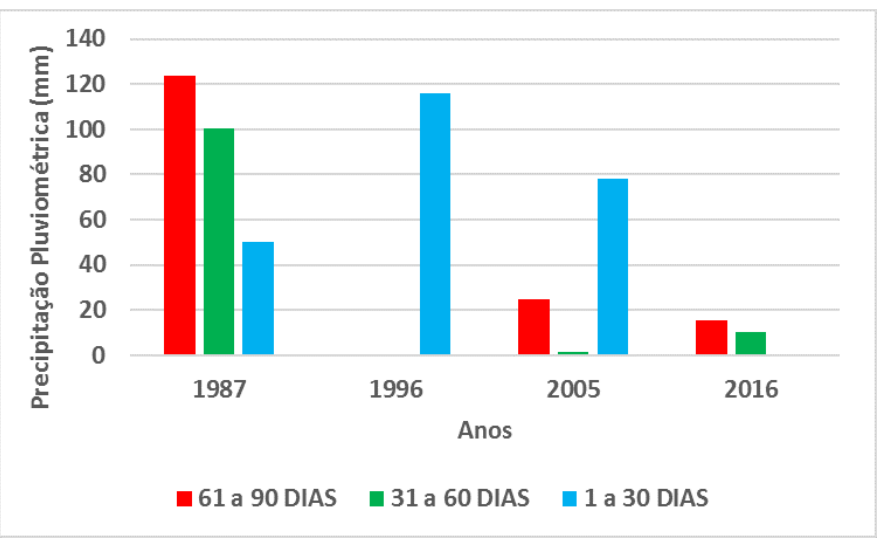

Fonte: Organização dos autores (2019). 
A Tabela 1 apresenta as classes de uso e cobertura das terras e os intervalos de classes do IVAS correspondente a cada tipologia de uso para Área de Monitoramento do Povoado de Simpatia. Para chegar aos valores de cada classe de uso e cobertura das terras na área de estudo foi aplicado o índice de Kappa para a imagem do ano de 2016. O índice de Kappa apresentou resultado de 0,86 (86\%), sendo considerado satisfatório de acordo o nível de concordância descrito no Quadro 3. Os intervalos dos anos 1987, 1996 e 2005 foram validados pela aplicação do índice Kappa na Estação de Monitoramento do Sítio Romão (Tabela 3). O resultado serviu para reforçar e validar a sensibilidade do IVAS no mapeamento de uso e cobertura das terras nos diferentes anos (1987, 1996, 2005 e 2016) na área de estudo.

Tabela 1 - Classes de uso e cobertura das terras e sua correlação com os valores do IVAS para Área de Monitoramento do Povoado de Simpatia

\begin{tabular}{llllll}
\hline Anos & Solo Exposto & $\begin{array}{l}\text { Agricultura } \\
\text { Pastagens } \\
\text { Caatinga } \\
\text { Gramíneo } \\
\text { Lenhosa }\end{array}$ & $\begin{array}{l}\text { Caatinga } \\
\text { Aberta }\end{array}$ & $\begin{array}{l}\text { Caatinga } \\
\text { Semiaberta }\end{array}$ & $\begin{array}{l}\text { Caatinga } \\
\text { Fechada }\end{array}$ \\
\hline 1987 & $<0,18$ & $0,18-0,296$ & $0,296-0,342$ & $0,342-0,43$ & $>0,43$ \\
1996 & $<0,18$ & $0,18-0,296$ & $0,296-0,342$ & $0,342-0,43$ & $>0,43$ \\
2005 & $<0,18$ & $0,18-0,296$ & $0,296-0,342$ & $0,342-0,43$ & $>0,43$ \\
2016 & $<0,124$ & $0,124-0,183$ & $0,183-0,211$ & $0,211-0,25$ & $>0,25$ \\
\hline
\end{tabular}

Fonte: Organização dos autores (2019).

A Figura 3 apresenta a distribuição espacial das classes de uso e cobertura das terras na Área de Monitoramento do Povoado de Simpatia, enquanto que, a Tabela 2 apresenta a quantificação de ocupação de cada classe de uso. Observa-se que no ano de 1987 predominava, na área de estudo, a Caatinga Semiaberta, com 5936,76 ha o que equivale 59,37\% da área, seguida pela Caatinga Fechada ocupando 3450,51 ha (34,5\%) e a Caatinga Aberta com 515,16 ha (5,15\%). As classes de Agricultura/ Pastagem/ Caatinga Gramíneo Lenhosa e Solo Exposto ocupavam uma pequena área no valor 93,15 ha (0,93\%) e 4,68 ha $(0,05 \%)$, respectivamente. 
Em 1996, nota-se aumento das áreas sob Caatinga Fechada (Figura 3 e Tabela 2), com valores que dobram sua área de abrangência, tornando-se a classe predominante no período, passando a ocupar 7111,53 ha o equivalente a $71,11 \%$ da área de estudo.

Figura 3 - Mapa de uso e ocupação das terras da área de Monitoramento do Povoado de Simpatia entre os anos de 1987 a 2016
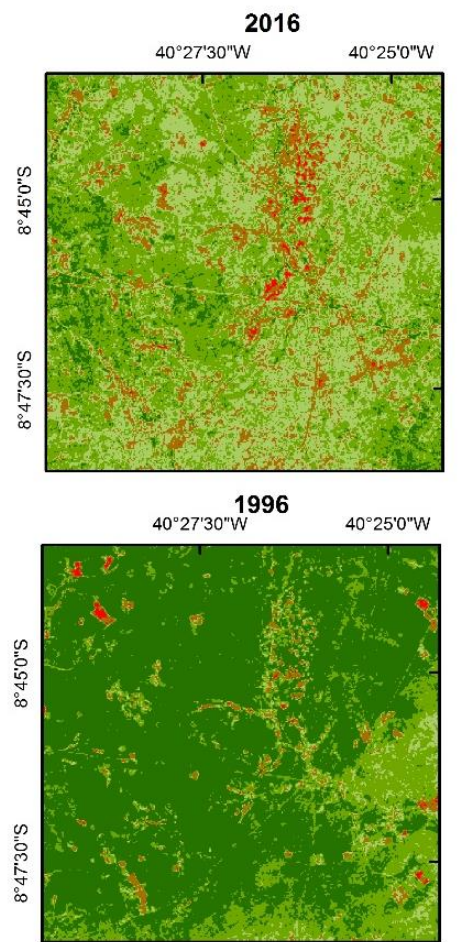
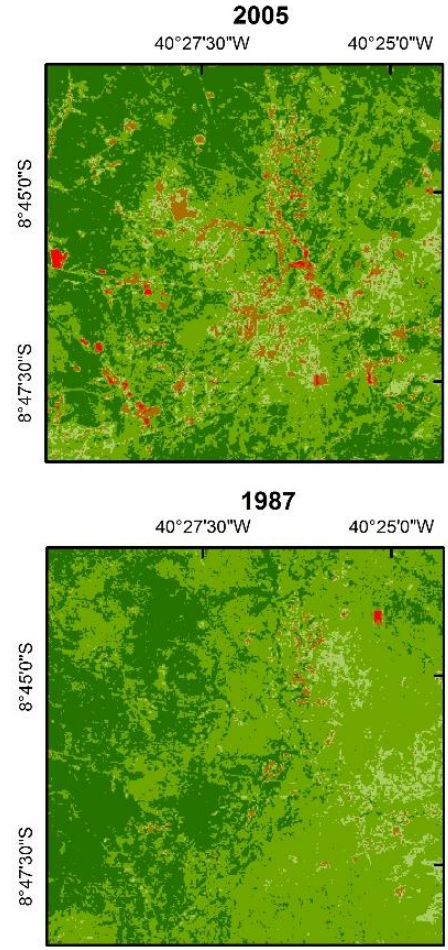

Legenda

Classes de Uso

Solo Exposto (SE)

Agricultura/ Pastagem /

Caatinga Gramíneo Lenhosa (A/P/CGL)

Caatinga Aberta (CA)

Caatinga Semi-Aberta (CSA)

Caatinga Fechada (CF)

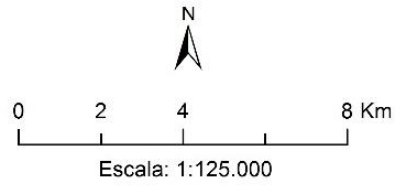

Sistema de Projeção Cartográfica

Datum SIRGAS-2000, Fuso 24s

Base Cartográfica: IBGE, 2010

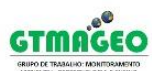

\section{PPGCTAS}

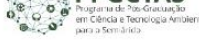

Fonte: Organização dos autores (2019).

Tabela 2 - Quantificação da ocupação das classes de uso das terras na Área de Monitoramento do Povoado de Simpatia entre os anos de 1987 a 2016.

\section{ANOS}

\begin{tabular}{lllllllll} 
TIPOS DE USO & \multicolumn{2}{c}{1987} & \multicolumn{2}{c}{1996} & \multicolumn{2}{c}{2005} & \multicolumn{2}{c}{2016} \\
& Área (ha) & Área (\%) & Área (ha) & Área (\%) & Área (ha) & Área (\%) & Área (ha) & Área (\%) \\
\hline CF & 3450,51 & 34,5 & 7111,53 & 71,11 & 4085,15 & 40,85 & 587,97 & 5,88 \\
CSA & 5936,76 & 59,37 & 2145,55 & 21,45 & 4427,55 & 44,27 & 4287,15 & 42,87 \\
CA & 515,16 & 5,15 & 449,01 & 4,49 & 856,17 & 8,56 & 3754,17 & 37,54 \\
A/P/CGL & 93,15 & 0,93 & 257,49 & 2,58 & 583,83 & 5,84 & 1305,36 & 13,05 \\
SE & 4,68 & 0,05 & 36,99 & 0,37 & 47,79 & 0,48 & 65,61 & 0,66 \\
\hline
\end{tabular}

Fonte: Organização dos autores (2019).

*ha (hectares) 
Por outro lado, a Caatinga Semiaberta diminuiu em mais da metade de sua área de abrangência passando a ocupar 2145,55 ha (21,45\%). Verifica-se que a diferença no aumento da Caatinga Fechada (3661,02 ha) é muito próxima da perda de áreas da Caatinga Semiaberta (3791,21 ha), o que indica queda no padrão da vegetação mais fechada durante o período entre 2005 a 2016. No entanto, essa tendência não acompanhou a Caatinga Aberta que teve sua área reduzida para 449,01 ha (4,49\%). Também, ocorreu um pequeno aumento das áreas mapeadas como Agricultura/ Pastagem/ Caatinga Gramíneo Lenhosa e de Solo Exposto, que passaram a ocupar 257,49 ha $(2,58 \%)$ e 36,99 ha $(0,37 \%)$, respectivamente.

Em 2005, é notória a redução das áreas ocupadas pela Caatinga Fechada e aumento da Caatinga Semiaberta que passaram a ocupar respectivamente, 4085, 15 ha (40,85\%) e 4427,55 ha $(44,27 \%)$. As demais classes de uso registraram aumento, sendo que a Caatinga Aberta passou a ocupar 856,17 ha (8,56\%), a Agricultura/ Pastagem/ Caatinga Gramíneo Lenhosa 583,83 ha (5,84\%) e as áreas de Solo Exposto alcançou 47,79 ha (0,48\%).

No ano de 2016, observa-se uma grande redução das áreas de Caatinga Fechada, a qual passou a ocupar apenas 587,97 ha, o que equivale a 5,88\% da área total. A Caatinga Semiaberta reduziu sua área para 4287,15 ha, mas ainda continuou sendo a classe predominante ocupando $42,87 \%$ do ambiente. Por outro lado, a Caatinga Aberta apresentou aumento de sua área se tornando a segunda maior classe de uso e ocupação presente em 3754,17 ha (37,54\%). As classes de Agricultura/ Pastagem/ caatinga gramíneo Lenhosa seguiram a tendência de aumento de suas áreas, apresentadas desde o início temporal desse estudo, sendo que a primeira mais que dobrou sua extensão chegando aos 1305,36 ha $(13,05 \%)$ e, a segunda, passou a abranger 65,61 ha $(0,66 \%)$.

Entre os períodos de 1987 a 2016, verificou-se que além da substituição da vegetação pela pastagem e/ou agricultura, conferiu-se tendência de alteração da estrutura das caatingas, onde as classes tiveram uma transição entre elas, porém prevalecendo, a substituição de áreas de Caatinga Fechada pela Caatinga Semiaberta e Aberta.

Após a quantificação das áreas referentes aos padrões de uso dos anos chaves selecionados para esse estudo, foi possível analisar o ganho e/ou perda de área por período em cada uma das classes de uso das terras (Figura 4) e, consequentemente, a taxa 
anual (Figura 5). Verifica-se que a Caatinga Fechada, a Caatinga Semiaberta e a Caatinga Aberta apresentaram períodos tanto de crescimento, quanto de redução de área entre os períodos, o que mostra uma grande variabilidade entre elas.

A Caatinga Fechada foi a classe que mais perdeu área ao longo dos quase 30 anos de estudo somando no total redução de 2862,54 ha. No entanto, considerando apenas os últimos 21 anos de análise verificou-se uma perda de 6523,56 ha. Apesar da maior perda de área pela Caatinga Fechada ter ocorrido no período de 2005 a 2016, onde 3497,13 ha foram substituídos por outros tipos de usos, a taxa anual de perda foi maior no período entre 1996 a 2005 quando, aproximadamente 369,08 ha ao ano foram perdidos (Figura 5).

Por outro lado, a Caatinga Aberta foi a classe que teve maior aumento de área, somando ao total um ganho de 3239,01 ha, sendo que 2898 ha aumentaram apenas nos últimos 11 anos, a uma proporção de 253,77 ha ao ano.

Figura 4 - Quantificação da mudança de uso e ocupação das terras em cada período de estudo na Área de Monitoramento do Povoado de Simpatia.

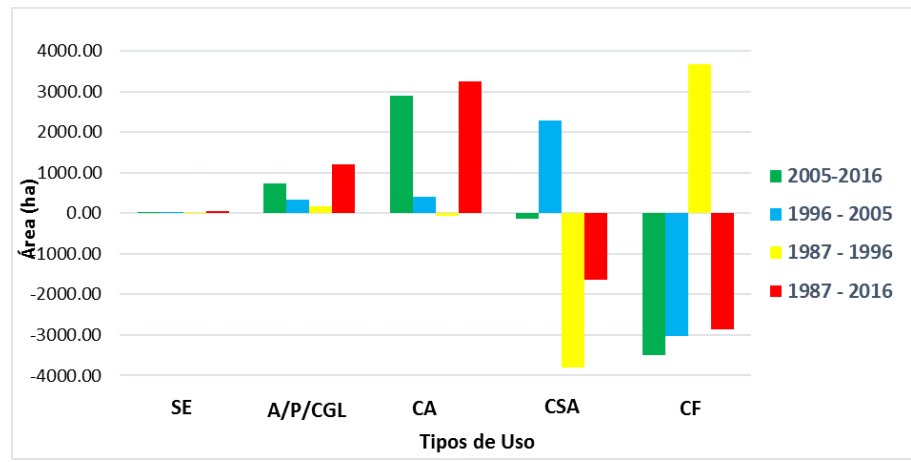

Fonte: Organização dos autores (2019).

Figura 5 - Taxa anual de mudança de uso e ocupação das terras em cada período de estudo na Área de Monitoramento do Povoado de Simpatia. 


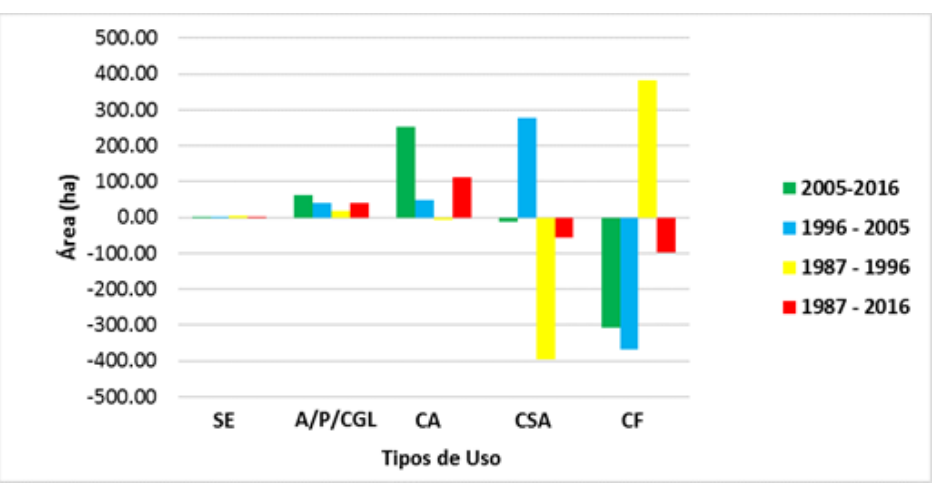

Fonte: Organização dos autores (2019).

As classes de Solo Exposto e Agricultura/ Pastagem/ Caatinga Gramíneo Lenhosa apresentaram tendência de aumento de áreas em todos os períodos de estudo, no entanto o aumento das regiões de Solo Exposto foi pequeno, visto que, em todo o período aumentou apenas 60,93 ha. Enquanto isso, a classe de Agricultura/ Pastagem/ Caatinga Gramíneo Lenhosa teve ganho de 1212,21 ha, dos quais 721,71 ha aumentaram nos últimos 11 anos, tendo uma proporção de 63,20 ha ao ano.

Resultado semelhante foi encontrado por Bittencurti et, al., (2017), que ao analisarem as mudanças da cobertura vegetal para os anos de 1980, 1990 e 2000, observaram que as três classes de caatingas nos municípios de Canindé do São Francisco e Poço Redondo, estado de Sergipe, diminuíram ao longo das décadas, sendo substituídas por áreas de pastagens.

Percebe-se ao longo do período de estudo, uma dinâmica de crescimento das áreas de Agricultura/ Pastagem/ Caatinga Gramíneo Lenhosa em substituição as demais classes de usos, principalmente, as caatingas de outros portes. No entanto, observa-se que prevalece uma tendência de diminuição da densidade da estrutura da vegetação, visto que, extensas áreas de Caatinga Fechada foram substituídas pelas caatingas Semiabertas e Abertas. Esse processo, também foi observado por Ballén et, al., (2016) que notaram uma perda de cobertura da vegetação das Caatingas mais densas ao longo dos anos 1989 a 2010 provocada por ações antrópicas na Área de Proteção Ambiental (APA) do Cariri, estado do Ceará.

Para buscar os principais agentes que dinamizam a estrutura de usos e cobertura das terras da área de estudo o primeiro passo foi uma análise dos condicionamentos 
pluviométricos. A Figura 6 apresenta a distribuição pluviométrica entre os anos de 1987 a 2016 para os meses de janeiro a abril e o último mês do ano anterior, ou seja, os cinco meses mais chuvosos no ano para a região de estudo. Observa-se que entre 1987 a 2005 dois dos anos estudados ficaram acima da média para o período e a maioria dos anos nesse período apresentaram chuvas acima da média, o que pode ter influenciado o crescimento das áreas de Caatinga Fechada nesse período.

Por outro lado, entre os anos de 2006 a 2016 o quantitativo de anos com chuva abaixo da média foram proporcionalmente maiores com destaque para os últimos cinco anos (Figura 6), os quais, segundo os estudos de Gondim et al. (2017) foram considerados secos com estiagem prolongada. Paralelamente, ao retornarmos para a distribuição da cobertura de uso das terras apresentadas anteriormente, pode-se atrelar a redução das chuvas a influência da redução das áreas de Caatinga Fechada nesse período.

Figura 6 - Distribuição das precipitações pluviométricas entre os anos de 1987 a 2016 no período chuvoso para a região de estudo.

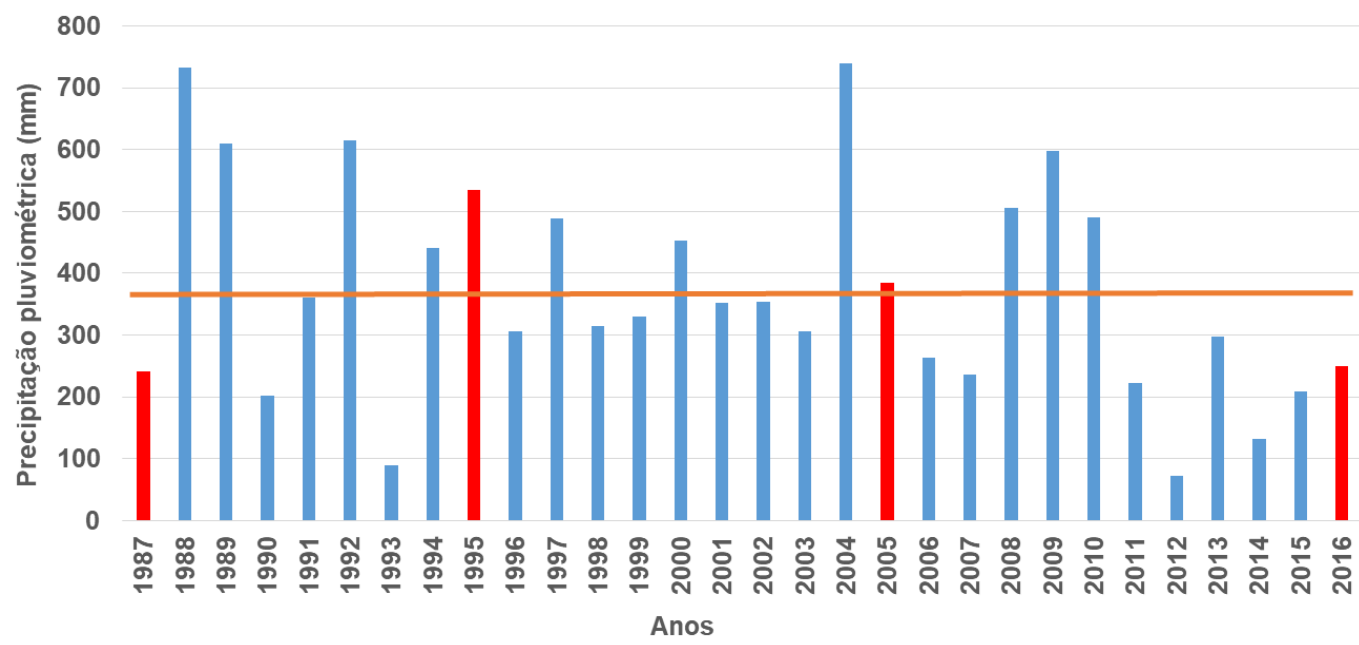

Fonte: Organização dos autores (2019).

Para verificar a influência das ações antrópicas foram levantados dados do IBGE sobre agropecuária na área de estudo. Para isso, analisou-se o histórico da quantidade de rebanho de caprinos, ovinos e bovinos no município de Petrolina (Figura 7) e a área de lavoura temporária e pastagens (Figura 8). 
Nota-se que ao longo do período de estudo, entre os anos de 2005 a 2016, uma diminuição do quantitativo de bovinos, porém um aumento no quantitativo de caprinos e ovinos (Figura 7). Apesar desses dados corresponderem ao município como um todo, acredita-se que o local de estudo acompanha essa tendência face as características observadas em campo.

\section{Figura 7 - Evolução do quantitativo de criação de caprinos, ovinos e bovinos no} município de Petrolina-PE entre os anos de 2005 a 2016.

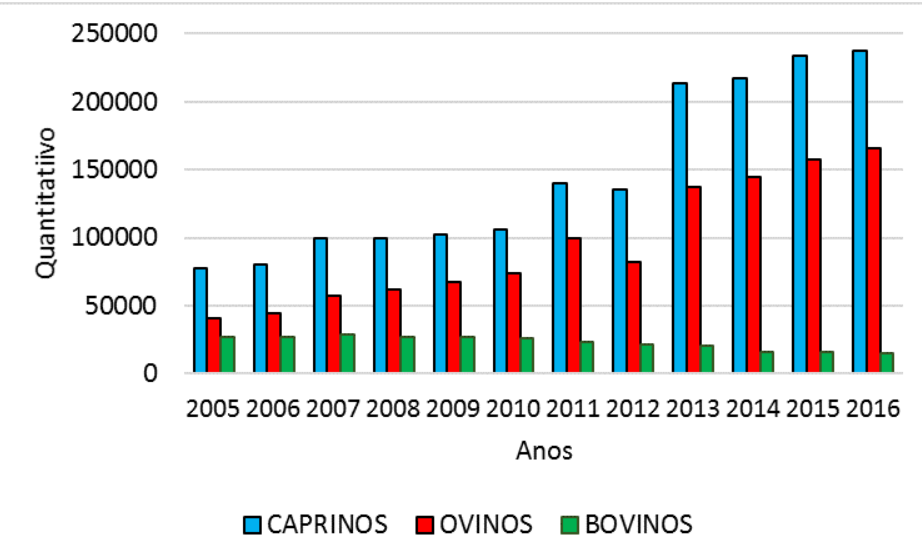

Fonte: IBGE (2018).

A sobrepastagem elimina o estrato herbáceo, reduzindo a diversificação florística, e o pisoteio excessivo pelos rebanhos resulta na compactação do solo e na degradação das terras impedindo a regeneração da vegetação nativa na área (DIAS \& BOCCHIGLIERI, 2016; SOUSA et, al., 2012). Nesse sentido, aponta-se que o aumento do rebanho contribui para diminuição da densidade das caatingas. Além disso, através de observações em campo, as áreas atualmente, ocupadas pela Agricultura/ Pastagem/ Caatinga Gramíneo Lenhosa são em grande parte composta por pastagens utilizadas para alimentação dos rebanhos.

Ao analisar os dados da Figura 8, observa-se uma diminuição das áreas cultivadas e, por outro lado, um aumento das áreas de pastagens entre o ano de 2006 e 2017 (um ano posterior as duas últimas imagens). 
Figura 8 - Evolução da lavoura temporária e pastagens não naturais no município de Petrolina-PE.

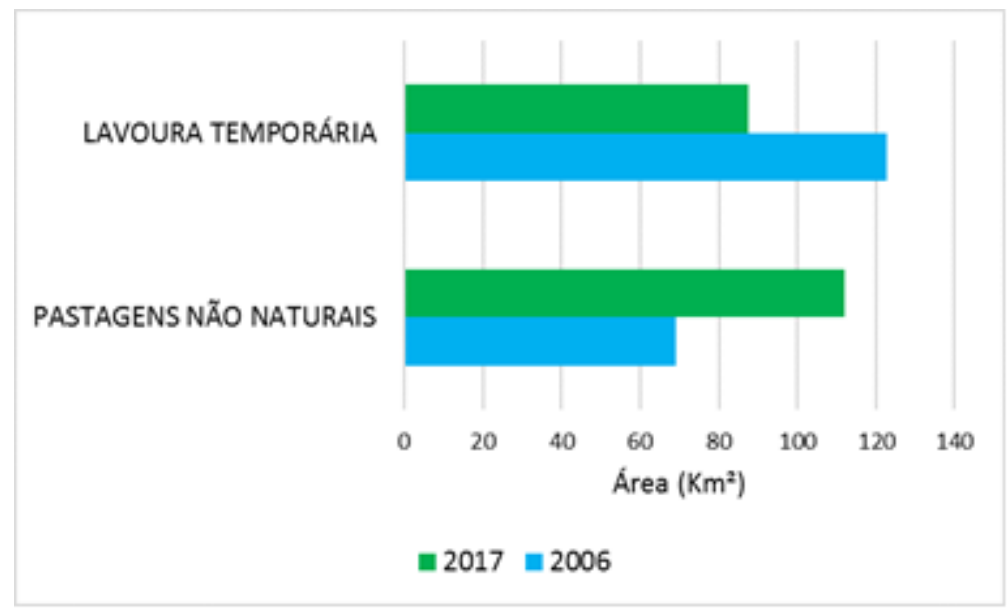

Fonte: IBGE (2018).

Assim, acredita-se que os baixos índices pluviométricos nos últimos 11 anos, potencializado pela sobrepastagem na região, foram as principais causas do processo de transformação da Caatinga Fechada em caatinga Semiaberta e Aberta na Área de Monitoramento do Povoado de Simpatia. A intensificação da atividade pecuarista também pode ser considerada um dos motivos para o aumento da Agricultura/ Pastagem/ Caatinga Gramíneo Lenhosa, visto que, para atender a demanda do aumento dos rebanhos as caatingas foram substituídas por áreas de pastagens, compostas principalmente pelo capim-buffel (Cenchrus Ciliares).

Destacam-se que a diminuição da cobertura vegetal e a variação na composição de espécies são indicadores sensíveis da desertificação (JOSEPH et, al. 2018) e a transformação de florestas para outros usos das terras tende a acelerar esse processo (WIJITKOSUM, 2016). Apesar de não haver uma grande área desertificada na região de estudo, a diminuição da densidade da vegetação evidencia um baixo índice de regeneração da vegetação e, esse processo, associado ao desmatamento para uso agropecuário eleva os riscos à desertificação local. 


\subsection{Mudanças de uso das terras na área de monitoramento do povoado de Simpatia}

Ao analisar os índices pluviométricos (Figura 9) para a Estação de Monitoramento do Sítio Romão verificou-se que as imagens dos anos de 1987, 1997 e 2018 foram coletadas em período com alta precipitação pluviométrica antecedente e no ano de 2007 com baixa concentrações de chuvas antecedente.

Figura 9 - Quantificação das precipitações pluviométricas no município de Afrânio-PE dos dias antecedentes à imagem de acordo com dados da APAC-PE.

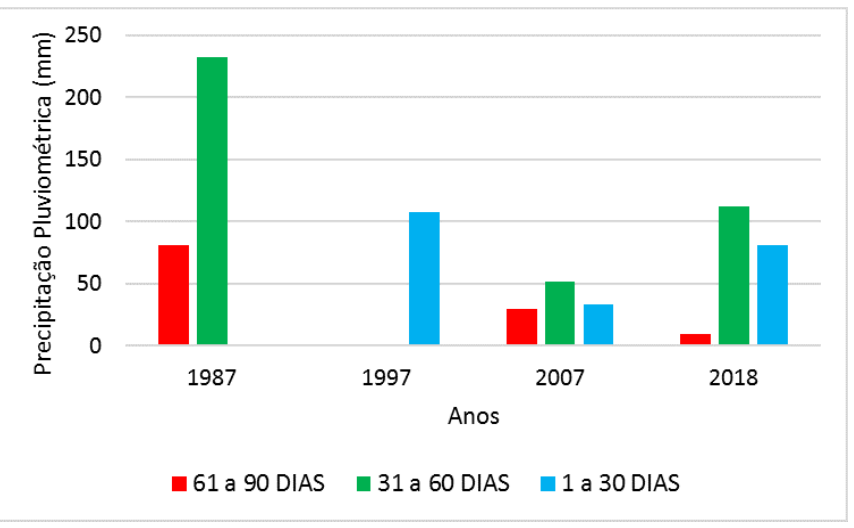

Fonte: Organização dos autores (2019).

A Tabela 3 apresenta as classes de uso e cobertura das terras e os intervalos de classes do IVAS correspondentes a cada tipologia de uso das terras para Estação de Monitoramento do Sítio Romão. Para chegar aos valores de cada classe de uso e cobertura na área de estudo foi aplicado o índice de Kappa para imagem do ano de 2018. O índice de Kappa apresentou resultado de 0,84 (84\%), sendo considerado satisfatório de acordo com o nível de concordância descrito no Quadro 3. Os intervalos da imagem de 2018 foram replicados para as imagens dos anos 1987 e 1997. Em 2007 desenvolveu o ajuste de Intervalos para imagens de baixa precipitação antecedente e após aplicação do índice de Kappa chegou ao resultado de 0,86 (86\%).

A Tabela 3 apresenta as classes de uso e cobertura das terras e os intervalos de classes do IVAS correspondentes a cada tipologia de uso das terras para Estação de Monitoramento do Sítio Romão. Para chegar aos valores de cada classe de uso e cobertura na área de estudo foi aplicado o índice de Kappa para a imagem do ano de 2016. O índice 
de Kappa apresentou resultado de 0,84 (84\%), sendo considerado satisfatório de acordo com o nível de concordância descrito no Quadro 3. O resultado serviu para reforçar e validar a sensibilidade do IVAS no mapeamento de uso e cobertura das terras nos diferentes anos (1987, 1996, 2005 e 2016) na área de estudo.

Tabela 3 - Classes de uso e cobertura das terras e sua correlação com os valores do IVAS para a Estação de Monitoramento da Microbacia do Sítio Romão

\begin{tabular}{llllll}
\hline Anos & $\begin{array}{l}\text { Solo } \\
\text { Exposto }\end{array}$ & $\begin{array}{l}\text { Agricultura / } \\
\text { Pastagens / } \\
\text { Caatinga } \\
\text { Gramíneo } \\
\text { Lenhosa }\end{array}$ & $\begin{array}{l}\text { Caatinga } \\
\text { Aberta }\end{array}$ & $\begin{array}{l}\text { Caatinga } \\
\text { Semiaberta }\end{array}$ & $\begin{array}{l}\text { Caatinga } \\
\text { Fechada }\end{array}$ \\
\hline 1987 & $<0,18$ & $0,18-0,296$ & $0,296-0,342$ & $0,342-0,43$ & $>0,43$ \\
1997 & $<0,18$ & $0,18-0,296$ & $0,296-0,342$ & $0,342-0,43$ & $>0,43$ \\
2007 & - & $<0,27$ & $0,27-0,295$ & $0,295-0,363$ & $>0,363$ \\
2018 & $<0,18$ & $0,18-0,296$ & $0,296-0,342$ & $0,342-0,43$ & $>0,43$ \\
\hline
\end{tabular}

Fonte: Organização dos autores (2019).

A partir dos mapas apresentados na Figura 10 e quantificados na Tabela 4, no ano de 1987, predominava na área de estudo, a Caatinga Fechada, com 236,07 ha o que equivalia a $58,58 \%$ da área, seguida pela Caatinga Semiaberta ocupando 152,46 ha (37,83\%). As classes de Caatinga Aberta e Agricultura/ Pastagem/ Caatinga Gramíneo Lenhosa ocupavam respectivamente, uma área de 9,27 ha (2,3\%) e 5,04 ha (1,25\%). As áreas de Solo Exposto ocupavam apenas 0,18 ha o que equivalia apenas a 0,04\% da área total.

Figura 10 - Figura 10 - Mapa de Uso e Ocupação das Terras da Estação de Monitoramento da Microbacia do Sítio Romão entre os anos de 1987 a 2018 

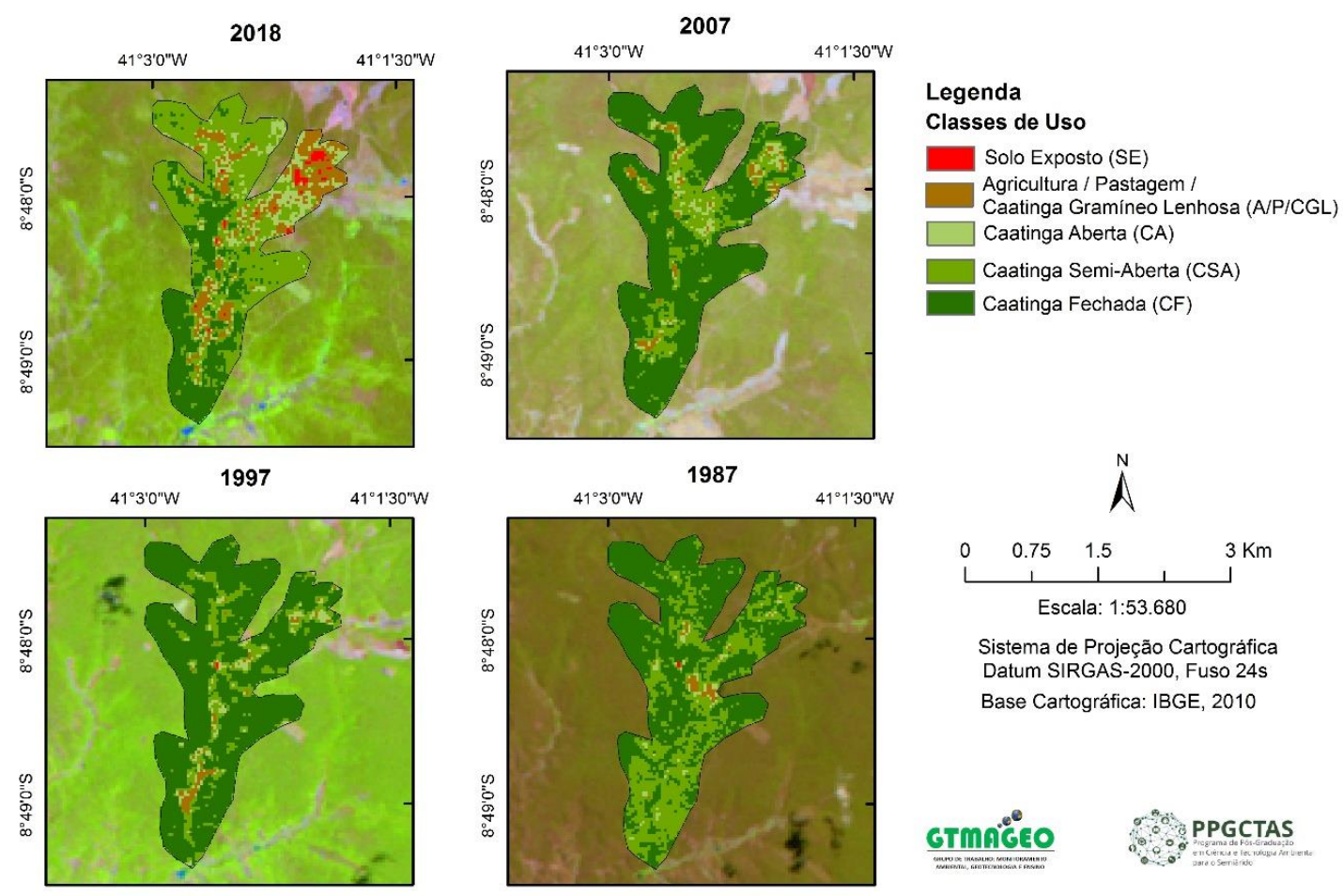

Fonte: Organização dos autores (2019).

Tabela 4 - Quantificação da dinâmica de classes de Uso e Ocupação das Terras da Estação de Monitoramento da Microbacia do Sítio Romão entre os anos de 1987 a 2018

\begin{tabular}{llllllllll}
\hline \multirow{2}{*}{ TIPOS DE USO } & \multicolumn{10}{c}{ ANOS } \\
& 1987 & & 1997 & \multicolumn{2}{c}{2007} & \multicolumn{2}{c}{2018} \\
& Área (ha) & Área (\%) & Área (ha) & Área (\%) & Área (ha) & Área (\%) & Área (ha) & Área (\%) \\
\hline CF & 236,07 & 58,58 & 317,88 & 78,88 & 291,78 & 72,4 & 100,62 & 24,97 \\
CSA & 152,46 & 37,83 & 60,48 & 15,01 & 80,46 & 19,97 & 178,83 & 44,37 \\
CA & 9,27 & 2,3 & 16,29 & 4,04 & 16,38 & 4,06 & 54,81 & 13,6 \\
A/P/CGL & 5,04 & 1,25 & 8,19 & 2,03 & 14,4 & 3,57 & 63,09 & 15,65 \\
SE & 0,18 & 0,04 & 0,18 & 0,04 & 0 & 0 & 5,67 & 1,41 \\
\hline
\end{tabular}

*ha (hectares)

Fonte: Organização dos autores (2019).

Em 1997, observa-se um aumento da Caatinga Fechada, a qual passou a ocupar 317,88 ha equivalente a $78,91 \%$ da área de estudo. Enquanto que, as áreas de Caatinga Semiaberta foram reduzidas em mais da metade em comparação ao ano de 1987 ocupando 60,48 ha, o que equivale a $15,01 \%$ da área total de estudo. Nota-se um pequeno aumento das classes de Caatinga Aberta e de Agricultura/ Pastagem/ Caatinga Gramíneo 
Lenhosa, as quais passaram a ocupar respectivamente, 16,29 ha $(4,04 \%)$ e 8,19 ha $(2,03 \%)$. A classe de Solo Exposto manteve a mesma área em 1987.

No ano de 2007, verifica-se uma pequena redução das Caatingas Fechadas, no entanto, essa classe continuou predominante nesse período ocupando 291,78 ha (72,4\%). As classes de Caatinga Semiaberta e Agricultura/ Pastagem/ Caatinga Gramíneo Lenhosa tiveram suas áreas ampliadas passando a ocupar, respectivamente 80,46 ha $(19,97 \%)$ e 14,4 ha (3,57\%). A Caatinga Aberta, também, aumentou sua área, porém esse aumento foi pequeno passando a ocupar 16,38 ha (4,06\%). Não foi encontrado nesse período área de com nítido Solo Exposto.

Ao comparar a localização da área de Solo Exposto em 1987 e 1997 verificou-se que essa passou a ser classificada como área de Agricultura/ Pastagem/ Caatinga Gramíneo Lenhosa o que pode ser atribuído a possível crescimento de pequenos arbustos que alterou as respostas espectrais das antigas áreas de Solo Exposto.

Em 2018 foi notório grande redução das áreas de Caatinga Fechada passando a ocupar apenas 100,62 ha (24,97\%). Por outro lado, a Caatinga Semiaberta teve aumento de sua área de abrangência, ocupando 178,93 ha, o que equivale a 44,37\%, tornando-se predominante no período. As classes de Caatinga Aberta e Agricultura/ Pastagem/ caatinga Gramíneo Lenhosa, também obtiveram aumentos de suas áreas passando a ocupar respectivamente, 54,81 ha $(13,6 \%)$ e 63,09 ha $(15,65 \%)$. Destaca-se que nesse estudo foi a primeira vez que a área ocupada pela Agricultura/ Pastagem / Caatinga Gramíneo Lenhosa se apresentou mais abrangente em comparação com a Caatinga Aberta. Nesse período, houve também o aparecimento de uma área significativa de solo exposto ocupando 5,67 ha $(1,41 \%)$.

Durante todo período de estudo (1987 a 2018), foi verificada uma variabilidade das transições das classes de caatingas e, um aumento progressivo das áreas de Agricultura/ Pastagem/ Caatinga Gramíneo Lenhosa.

Após quantificar a área das classes em cada ano da imagem, foi possível analisar o ganho e/ou perda de área por período em cada uma das classes (Figura 11) e consequentemente, a taxa anual (Figura 12). Verifica-se que a Caatinga Fechada, e a Caatinga Semiaberta apresentaram períodos tanto de aumento, quanto de redução de 
24 | Análise da estrutura e distribuição da cobertura vegetal das caatingas em diferentes áreas de sequeiro no Vale do São Francisco (Bahia e Pernambuco) nas últimas três décadas

áreas entre os períodos, o que mostra uma grande variabilidade entre elas. As demais classes seguiram uma tendência de aumento entre os períodos,

A Caatinga Fechada foi a classe que mais perdeu área ao longo dos quase 30 anos, somando no total redução de 135,45 ha, o que equivale a uma perda anual de 4,39 ha ao ano. No entanto, considerando apenas os últimos 11 anos de estudo, verificou-se diminuição de 191,16 ha, o que representa uma taxa de redução de 17,12 ha por ano. Essa redução impulsionou o aumento de 26,37 e 45,54 ha de Caatinga Semiaberta e Caatinga Aberta, respectivamente ao longo dos 30 anos de estudo.

Figura 11 - Quantificação da mudança de uso e ocupação das terras em cada período na Estação de Monitoramento do Sítio Romão

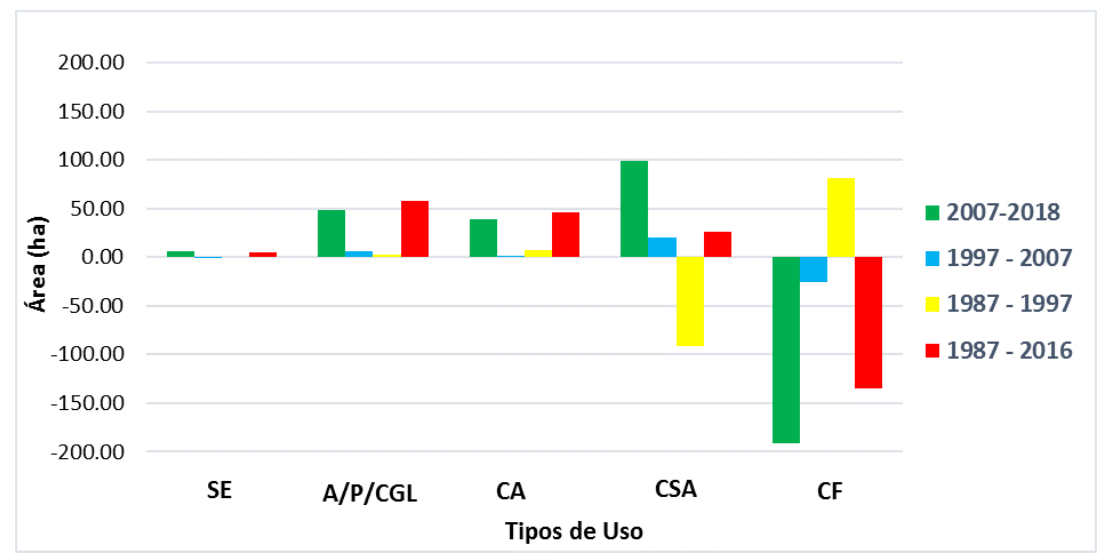

Fonte: Organização dos autores (2019).

Figura 12 -Taxa anual de mudança de uso e ocupação das terras em cada período na Estação de Monitoramento do Sítio Romão

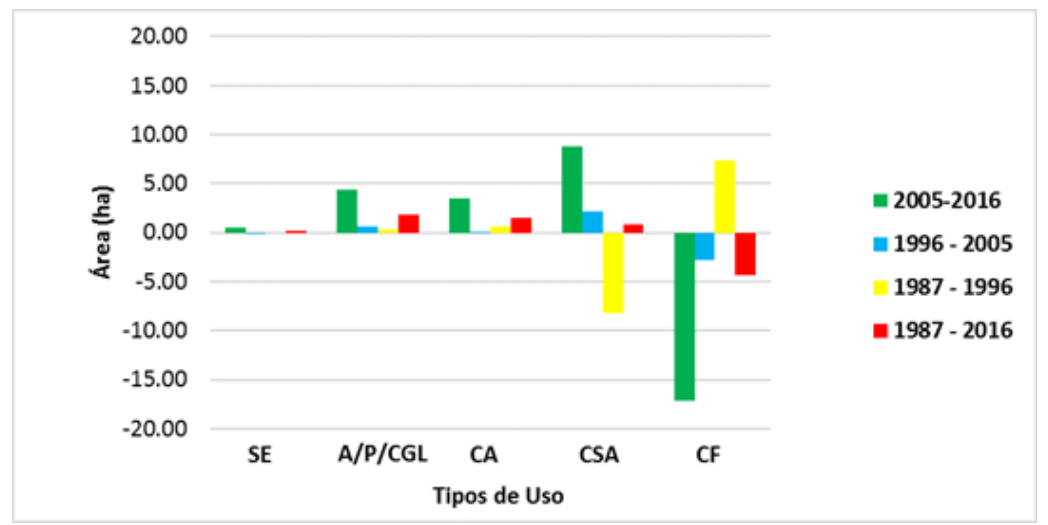

Fonte: Organização dos autores (2019). 
A dinâmica apresentada demonstra que há tendência de diminuição da densidade das classes de caatingas principalmente, no último período do estudo. Como até 2007 as áreas de Caatinga Fechada eram predominantes a transição da Caatinga Fechada para Caatinga Semiaberta justifica o fato dessa última ter apresentado maior ganho de área se tornado a classe mais abrangente na Estação de Monitoramento da Microbacia do Sítio Romão.

Destaca-se que a diminuição da densidade das Caatingas, também foi observada na área de Monitoramento do Povoado de Simpatia, e quando a Caatinga Semiaberta se tornou predominante e a tendência de diminuição continuou, a Caatinga Aberta aumentou consideravelmente. Assim, é motivo de alerta que essa tendência continue na Estação de Monitoramento da Microbacia do Sítio Romão.

Nota-se também na Estação de Monitoramento da Microbacia do Sítio Romão uma alta taxa de desmatamento, visto que, a classe de Agricultura / Pastagem / Caatinga Gramíneo Lenhosa foi a classe que teve as maiores ampliações de área, somando um ganho de 58,05 ha². Esse aumento ocorreu principalmente nos últimos 11 anos onde 48,69 ha de áreas de caatingas foram substituídas pela citada classe a uma taxa anual de 4,36 ha. Soma-se a isso, o reaparecimento de áreas de Solo Exposto, no entanto em uma abrangência maior que nos anos de 1997 e 1987, ocupando 5,67 ha.

Observando a distribuição da precipitação pluviométrica na Figura 6, percebe-se que o ano de 2007 as chuvas estiveram abaixo da média e, em 2018, segundo Paranhos (2019) foi um ano considerado seco, porém com chuvas superiores em boa parte do semiárido brasileiro, incluindo a região de Petrolina, Pernambuco.

A baixa pluviosidade pode ter influenciado na considerável diminuição das Caatingas Fechadas nesse período conforme constatação nesse estudo. Por outro lado, no período de 1987 a 1997, em seis dos onze anos foram considerados chuvosos, o que pode explicar o ganho de área das Caatingas Fechadas nesse período.

Ao ser levantado o histórico da quantidade de rebanho de Caprinos, Ovinos e Bovinos no município de Casa Nova-BA (Figura 13) e a área de lavoura e pastagens temporárias, que são as principais atividades agrícolas presentes na Estação de Monitoramento da Microbacia do Sítio Romão (Figura 14), percebe-se ao longo do 
período de estudo (2006 a 2017) oscilações entre ganhos e perdas do rebanho, porém desde 2012 há tendência de aumento do rebanho de caprinos e ovinos. Acredita-se que o local de estudo acompanha essa tendência do município face as características observadas em campo.

Assim, acredita-se que o aumento do rebanho possa, além de ter contribuído para diminuição da densidade das caatingas, como também ser o principal responsável para o aumento da classe de Agricultura/ Pastagem/ Caatinga Gramínea Lenhosa.

De acordo com a Figura 14, apesar da área de lavoura temporária ser bem maior que as áreas de pastagens, a primeira teve sua área reduzida, enquanto aumentaram as áreas de pastagem acima da redução das áreas de lavoura. Acredita-se então que esse aumento das pastagens no município se deve a necessidade de suprir o aumento do rebanho. Acrescenta-se ainda que o aumento das áreas de pastagens nas caatingas resultam em parte da crescente demanda por alimentos (RIBEIRO et, al,. 2016).

Figura 13 - Evolução da quantidade do rebanho de Caprino, Ovino e Bovino no município de Casa Nova - BA de 2006 a 2017.

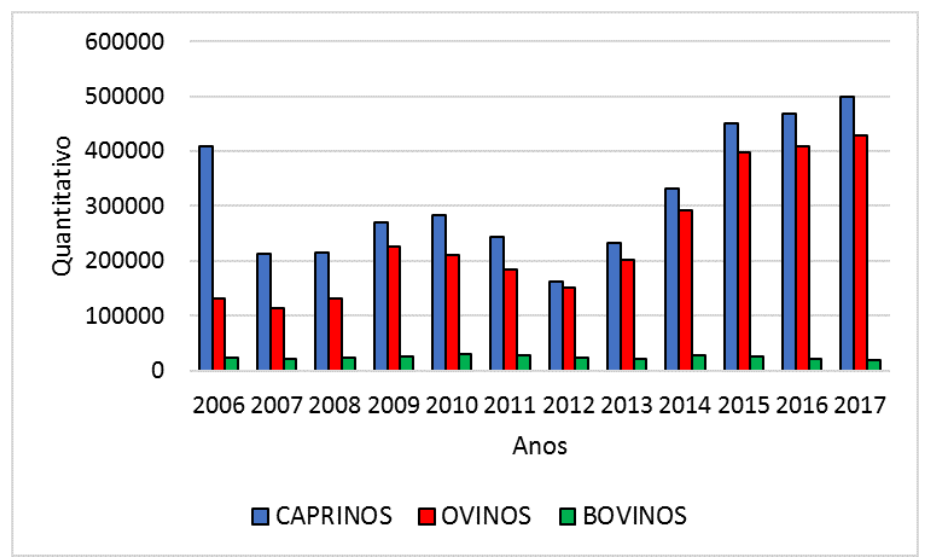

Fonte: IBGE (2018). 
Figura 14 - Evolução da lavoura temporária e pastagens não naturais no município de

Casa Nova - BA

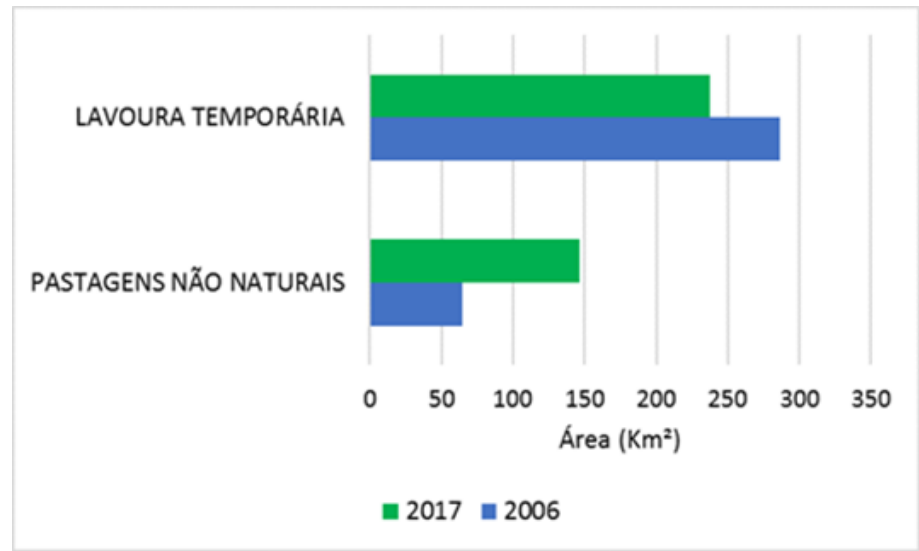

Fonte: IBGE (2018).

Assim, a redução dos totais pluviométricos potencializado pelas ações antrópicas pode explicar a diminuição da densidade da cobertura vegetal formadas pelas caatingas na Estação de Monitoramento da Microbacia do Sítio Romão.

\section{CONSIDERAÇÕES FINAIS}

A abordagem multitemporal permitiu compreender a dinâmica das mudanças de uso e ocupação das terras ao longo do tempo e, correlacionar os dados obtidos com observações em campo, o que subsidia ao pesquisador verificar o que motivam as mudanças.

No Domínio da caatinga há limitação para o estudo da vegetação por Sensoriamento Remoto devido a sua característica caducifólia, o que diminui as opções de imagem, pois é ideal que o monitoramento seja realizado no período chuvoso. Porém, esse período se limita a três ou quatro meses do ano e nesse período coincide muitas vezes com grande interferência de nuvens. Por isso, é importante as análises dos dados pluviométricos, principalmente nos noventa dias que antecedem a captura da imagem orbital.

Quando não é possível analisar uma imagem orbital no período chuvoso, o método de Ajuste de Intervalos de Classes, proposto nesse estudo, mostrou-se eficiente na análise da vegetação no período seco. Destaca-se que essa metodologia só foi possível porque 
entende-se que as imagens estavam próximas do período chuvoso, e assim a vegetação ainda não tinha perdido todas sua estrutura foliar.

Assim, a metodologia empregada permitiu alcançar o objetivo proposto, tendo sido possível verificar mudanças no padrão fisionômico da vegetação nas áreas estudadas ao longo do período de estudo. Como citado anteriormente, não foi diagnosticado grandes áreas desertificadas, porém a diminuição da densidade vegetal e a alta taxa de desmatamento, aliado as condições climáticas, aumentam, as possíveis contribuições ao processo de desertificação nas áreas de estudo.

Quando comparado as duas áreas de estudo verificou-se que a soma da proporção das classes de Caatinga Fechada, Caatinga Semiaberta e Caatinga Aberta são semelhantes, visto que, na Estação de Monitoramento da Microbacia do Sítio Romão as citadas classes somadas representou $82,94 \%$ da área em 2018, enquanto que, na área de Monitoramento do Povoado de Simpatia essa soma representou 86,29\% da área no ano de 2016.

No entanto, as áreas de estudo se diferenciam pela densidade da vegetação, visto que a Estação de Monitoramento da Microbacia do Sítio Romão apresenta uma vegetação mais densa comparada com a área de Monitoramento do Povoado de Simpatia. Essa afirmativa é observada pela proporção de Caatinga Fechada e Caatinga Aberta. Já na Estação de Monitoramento da Microbacia do Sítio Romão essas classes equivalem, consequentemente a $24,97 \%$ e $13,06 \%$ da área em 2018. Na área de Monitoramento do Povoado de Simpatia em 2016, apenas 5,88\% da área era ocupada pela Caatinga Fechada, e a Caatinga Aberta representava 37,54\% da área total. Esse fator ocorreu devido um maior quantitativo pluviométrico e a disponibilidade hídrica devido à influência dos corpos hídricos da microbacia na Estação de Monitoramento do Sítio Romão.

A redução das caatingas e, a exposição anual crescente dos solos aos intempéries pluviométricos, pode contribuir para o processo de desertificação. Acrescenta-se a isso, que a redução das caatingas também, pode afetar a biodiversidade florística que pode contribuir, também no processo de desertificação local.

O mapeamento temporal em áreas de monitoramento de pequena extensão, permite verificar a dinâmica local e os fatores que influenciam possíveis impactos nas caatingas. Nesse sentido as informações levantadas nesse estudo podem contribuir para o 
desenvolvimento de estratégias e políticas públicas voltadas à conservação da vegetação local e outras áreas de características semelhantes.

\section{AGRADECIMENTOS}

Os autores agradecem a CAPES (Coordenação de Aperfeiçoamento de Pessoal de Nível Superior) financiadora do Programa de Pós-Graduação em Ciência e Tecnologia Ambiental para o Semiárido (PPGCTAS) da UPE, uma vez que este trabalho está relacionado à dissertação de mestrado do primeiro autor, desenvolvida junto ao PPGCTAS.

\section{REFERÊNCIAS}

AIDE, T. M.; CLARK, M. L.; GRAU, D. L.; LEVY, M. A.; REDO, D.; BONILLA-MOHENO, M.; RINER, G.; ANDRADE-NUÑEZ, M. J.; MUÑIZ, M. Deforestation and Reforestation of Latin America and the Caribbean (2001-2010). Biotropica, vol.45, n.2, p.262-271, 2013.

ALI, A.; HALLETT, S.; BREWER, T. Using vegetation indices for the estimation and production of vegetation cover maps in the Jeffara Plain, Libya. Journal of Environmental Science, Toxicology and Food Technology, vol.12, n.2, p.23-28, 2018.

ALLEN, R.; TASUMI, M.; TREZZA, R. Sebal Surface Energy Balance Algorithm for Land: Advanced Training and Users Manual. Idaho: Idaho: The Idaho Department of Water Resources, 2002. Disponível em: <http://www,posmet,ufv,br/wp-content/uploads/2016/09/MET-479-Waters-et-alSEBAL,pdf $>$. Acesso em: 25 ago, 2018.

ANTONGIOVANNI, M.; VENTICINQUE, E. M.; FONSECA, C. R. Fragmentation patterns of the Caatinga drylands. Landscape Ecology, vol.33, p.1353-1367, 2018.

APAC-PE, Agência Pernambucana de Águas e Clima. Monitoramento pluviométrico. Disponível em: <http://www,apac,pe,gov,br/meteorologia/monitoramento-pluvio,php>, Acesso em: 12 dez, 2018 ,

BALLÉN, L. A. C.; SOUZA, B. I.; LIMA, E. R. V. Análise espaço-temporal da cobertura vegetal na área de proteção ambiental do Cariri, Paraíba, Brasil. Boletim Goiano de Geografia, vol.36, n.3, p.555$571,2016$.

BECERRA, J. A. B. Influence of the rainfall seasonal variability in the caatinga vegetation of ne Brazil by the use of time-series. Journal of Hyperspectral Remote Sensing, vol.4, n.1, p.31-44, 2014.

BELTRÃO, B. A. et. al. Projeto cadastro de fontes de abastecimento por água subterrânea, Diagnóstico do município de Afrânio, estado de Pernambuco. Recife: CPRM/PRODEEM, 22p, 2005a.

BELTRÃO, B. A. et. al. Projeto cadastro de fontes de abastecimento por água subterrânea, Diagnóstico do município de Petrolina, estado de Pernambuco. Recife: CPRM/PRODEEM, 41p, 2005b. 
BEUCHLE, R. GRECCHI, R. C.; SHIMABUKURO, Y. E.; SELIGER, R.; EVA, H. D.; SANO, E.; ACHARD, F. Land cover changes in the Brazilian Cerrado and Caatinga biomes from 1990 to 2010 based on a systematic remote sensing sampling approach. Applied Geography, vol.58, p.116-127, 2015.

BITENCURTI, D. P. et al. Análise multitemporal do desmatamento nos municípios de Canindé de São Francisco e Poço Redondo, SE. Geosul, vol.32, n.63, p.117-139, 2017.

CASTELLETTI, C. H. M. et al. Quanto ainda resta da Caatinga? Uma estimativa preliminar. In: LEAL, I. R. et al. (Ed). Ecologia e conservação da Caatinga. Recife: EDUFPE, p.695-715, 2013.

CAVALCANTI, L. C. S. Cartografia de paisagens. São Paulo: Oficina de Textos, 2014.

CHANDER, G.; MARKHAM, B. Revised Landsat-5 TM radiometric calibration procedures and postcalibration dynamic ranges. IEEE Transactions on geoscience and remote sensing, vol.41, n.11, p.2674-2677, 2003.

COHEN, J. A. coefficient of agreement for nominal scales. Educational and Psychological Measurement, vol.20, n.1, p.37-46, 1960.

COUTINHO, L. M. O conceito de bioma. Acta botanica brasílica, vol.20, n.1, p.3-23, 2006.

DIAS, D. M.; BOCCHIGLIERI A. Riqueza e uso do habitat por mamíferos de médio e grande porte na Caatinga, nordeste do Brasil. Neotropical Biology and Conservation, vol.11, n.1, p.38-46, 2016.

FATIHA, B.; ABDELKADER, A.; LATIFA, H.; MOHAMED, E. Spatio temporal analysis of vegetation by vegetation indices from multi-dates satellite images: application to a semi arid area in ALGERIA. Energy Procedia, vol.36, p.667-675, 2013.

FERNANDES, M. R. M.; MATRICARDI, E. A. T.; ALMEIDA, A. Q.; FERNANDES, M. M. Mudanças do uso e de cobertura da terra na região semiárida de Sergipe. Floresta e Ambiente, Rio de Janeiro, vol.22, n.4, p.472-482, 2015.

GAMEIRO, S.; TEIXEIRA, C. P. B.; SILVA NETO, T. A.; LOPES, M. F. L.; DUARTE, C. R.; SOUTO, M. V. S.; ZIMBACK, C. R. L. Avaliação da cobertura vegetal por meio de índices de vegetação (NDVI, IVAS e IAF) na Sub-Bacia Hidrográfica do Baixo Jaguaribe - CE. Terrae, vol.13, n.1-2, p.15-22, 2016.

IBGE, Instituto Brasileiro de Geografia e Estatística. Cidades. Rio de Janeiro: IBGE, Disponível em: <www,ibgecidades,com,br>, Acesso em: 08 out, 2018.

HOMOLOVÁ, L.; JANOUTOVÁ, R.; LUKEŠ, P.; HANUŠ, J.; NOVOTNÝ, J.; BROVKINA, O.; FERNANDEZ, R. R. L. In situ data supporting remote sensing estimation of spruce forest parameters at the ecosystem station. Bílý Kř́rž, Beskydy, vol.10, n.1-2, p.75-86, 2018.

HUETE, A. R. A. soil-adjusted vegetation index (IVAS). Remote sensing of environment, vol.25, n.3, p.295-309, 1988.

LOPES, R. J. C.; SANTOS, A. M. DOS; ZLATAR, T.; LIMA JÚNIOR, C. DE. Uso de índices de vegetação por sensoriamento remoto para estudos da Caatinga: uma revisão sistemática. Gaia Scientia, vol.14, n.1, p.104-116, 2020.

JANSSEN, T. A. J. et al. Extending the baseline of tropical dry forest loss in Ghana (1984-2015) reveals drivers of major deforestation inside a protected area. Biological Conservation, vol.218, p.63-172, 2018. 
JOSEPH, O.; GBENGA, A. E.; LANGYIT, D. G. Desertification risk analysis and assessment in Northern Nigeria, Remote Sensing Applications. Society and Environment, vol.11, p.70-82, 2018.

LANDIS, J. R.; KOCH, G. G. An application of hierarchical kappa-type statistics in the assessment of majority agreement among multiple observers. Biometrics, p.363-374, 1977.

LÓPEZ-BARRERA, F.; MANSON, R. H.; LANDGRAVE, R. Identifying deforestation attractors and patterns of fragmentation for seasonally dry tropical forest in central Veracruz, Mexico. Land Use Policy, vol.41, p.274-283, 2014.

LQBALL, M. An Introduction to Solar Radiation. New York: Academic, 1983, 390p.

MAYES, M. T. MUSTARD, J. F.; MELILLO, J. M. Forest cover change in Miombo Woodlands: modeling land cover of African dry tropical forests with linear spectral mixture analysis. Remote Sensing of Environment, vol.165, p.203-215, 2015.

MMA, Ministério do Meio Ambiente. Monitoramento do desmatamento nos biomas brasileiros por satélite. Monitoramento do bioma Caatinga. Brasília: MMA, 46p, 2011.

MORALES-BARQUERO, L.; BORREGO, A.; SKUTSCH, M.; KLEINN, C.; HEALEY, J. R. Identification and quantification of drivers of forest degradation in tropical dry forests: a case study in Western Mexico. Land Use Policy, vol.49, p.296-309, 2015.

PAUSE, M.; SCHWEITZER, C.; ROSENTHAL, M.; KEUCK, V.; BUMBERGER, J.; DIETRICH, P.; HEURICH, M.; JUNG, A.; LAUSCH, A. In situ/remote sensing integration to assess forest health. A review. Remote Sensing, vol.8, n.6, p.471, 2016.

PORTILLO-QUINTERO, C.; SMITH, V. Emerging trends of tropical dry forests loss in North \& Central America during 2001-2013: The role of contextual and underlying drivers. Applied Geography, vol.94, p.58-70, 2017.

REDO, D.; AIDE, T. M.; CLARK, M. L. Vegetation change in Brazil's dryland ecoregions and the relationship to crop production and environmental factors: Cerrado, Caatinga, and Mato Grosso, 2001-2009. Journal of land use science, vol.8, n.2, p.123-153, 2013.

RÊGO, S. C. A.; LIMA, P. P. S.; LIMA, M. N. S.; MONTEIRO, T. R. R.Análise comparativa dos índices de vegetação NDVI e IVAS no município de São Domingos do Cariri-PB. Revista geonorte, vol.2, n.4, p.1217-1229, 2012.

RIBEIRO, G. A. SILVA, J. N. C.; SILVA, J. B. Índice de Vegetação Ajustado ao Solo (IVAS): estado da arte e suas potencialidades. Revista Brasileira de Geografia Física, vol.9, n.06, p.2054-2074, 2016.

RIBEIRO, K; SOUZA-NETO, E. R.; CARVALHO JÚNIOR, J. A.; LIMA, J. R. S.; MENEZES, R. S. C.; DUARTENETO, P. J.; GUERRA, G. S.; OMETTO, J. P. H. B. Land cover changes and greenhouse gas emissions in two different soil covers in the Brazilian Caatinga, Science of The Total Environment, vol.571, p.1048-1057, 2016.

RITO, K. F.; TABARELLI, M.; LEAL, I. R. Euphorbiaceae responses to chronic anthropogenic disturbances in Caatinga vegetation: from species proliferation to biotic homogenization. Plant Ecology, vol.218, n.6, p.749-759, 2017.

SANTOS, F. D. A. Uso de índice espectral para monitoramento da cobertura vegetal no município de Juazeiro do Piauí. Revista de Geociências do Nordeste, vol.4, p.113-125, 2018. 
SANTOS, K. P.; SANTOS, A. M. Uso da terra, cobertura vegetal e desertificação no Projeto de Irrigação N11 - Petrolina - Pernambuco. Terr@plural, vol.13, n.2, p.385-399, 2019.

SCHULZ, C.; KOCH, R.; CIERJACKS, A.; KLEINSCHMIT, B. Land change and loss of landscape diversity at the Caatinga phytogeographical domain-analysis of pattern-process relationships with MODIS land cover products (2001-2012). Journal of Arid Environments, vol.136, p.54-74, 2017.

SILVA, R. M. P.; LIMA, J. R.; MENDONÇA, I. F. C. Alteração da cobertura vegetal na Sub-Bacia do Rio Espinharas de 2000 a 2010. Revista Brasileira de Engenharia Agrícola e Ambiental-Agriambi, vol.18, n.2, p.202-209, 2014.

SOUSA, F. P.; FERREIRA, T. O.; MENDONÇA, E. S.; ROMERO, R. E.; OLIVEIRA, J. G. B. Carbon and nitrogen in degraded Brazilian semi-arid soils undergoing desertification. Agriculture, Ecosystems \& Environment, vol.48, p.11-21, 2012.

SOUZA, M. E. Modelagem da dinâmica de uso e ocupação das terras em áreas susceptíveis a desertificação em municípios do semiárido pernambucano. 2019. 56p. Dissertação (Mestrado em Graduação em Ciência e Tecnologia Ambiental para o Semiárido) - Universidade de Pernambuco, Petrolina-PE.

UNCCD. United Nations Convention to Combat Desertification, Intergovernmental Negotiating Committee For a Convention to Combat Desertification, Elaboration of an International Convention to Combat Desertification in Countries Experiencing Serious Drought and/or Desertification, Particularly in Africa. U.N. Doc. A/AC.241/27, 33 I.L.M. 1328. New York: United Nations; 1994.

VALDEZ-HERNÁNDEZ, M.; SÁNCHEZ, O.; ISLEBE， G. A.; SNOOK, L. K.; NEGREROS-CASTILLO, P. Recovery and early succession after experimental disturbance in a seasonally dry tropical forest in Mexico. Forest ecology and management, vol.334, p.331-343, 2014.

VIEIRA A. T.; MELO F.; LOPES, H. B. V. V.; CAMPOS, J. C. V.; BOMFIM, L. F. C.; PEDRO ANTONIO DE ALMEIDA COUTO, P. A. A.; BEVENUTI, S. M. P. Projeto cadastro de fontes de abastecimento por água subterrânea, Diagnóstico do município de Casa Nova, Bahia. Salvador: CPRM/PRODEEM, 21p, 1995.

WIJITKOSUM, S. The impact of land use and spatial changes on desertification risk in degraded areas in Thailand. Sustainable Environment Research, vol.26, n.2, p.84-92, 2016. 